\title{
Effects of chronic carbon monoxide exposure on fetal growth and development in mice
}

\author{
Carolina C Venditti ${ }^{1}$, Richard Casselman ${ }^{1}$ and Graeme N Smith ${ }^{1,2^{*}}$
}

\begin{abstract}
Background: Carbon monoxide (CO) is produced endogenously, and can also be acquired from many exogenous sources: ie. cigarette smoking, automobile exhaust. Although toxic at high levels, low level production or exposure lends to normal physiologic functions: smooth muscle cell relaxation, control of vascular tone, platelet aggregation, anti- inflammatory and anti-apoptotic events. In pregnancy, it is unclear at what level maternal CO exposure becomes toxic to the fetus. In this study, we hypothesized that CO would be embryotoxic, and we sought to determine at what level of chronic CO exposure in pregnancy embryo/fetotoxic effects are observed.

Methods: Pregnant CD1 mice were exposed to continuous levels of CO (0 to $400 \mathrm{ppm}$ ) from conception to gestation day 17. The effect on fetal/placental growth and development, and fetal/maternal CO concentrations were determined.

Results: Maternal and fetal CO blood concentrations ranged from 1.12- 15.6 percent carboxyhemoglobin (\% $\mathrm{COHb}$ ) and 1.0- 28.6\% $\mathrm{COHb}$, respectively. No significant difference was observed in placental histological morphology or in placental mass with any CO exposure. At 400 ppm CO vs. control, decreased litter size and fetal mass ( $p<0.05)$, increased fetal early/late gestational deaths $(p<0.05)$, and increased CO content in the placenta and the maternal spleen, heart, liver, kidney and lung $(p<0.05)$ were observed.
\end{abstract}

Conclusions: Exposure to levels at or below 300 ppm CO throughout pregnancy has little demonstrable effect on fetal growth and development in the mouse.

\section{Background}

At very high levels, carbon monoxide $(\mathrm{CO})$ is a toxic gas; exogenous inhalation of CO levels higher than $3 \%$ (30 $000 \mathrm{ppm}$ ) leads to lethal outcomes [1], but this is usually through accidental inhalation of smoke or exhaust in enclosed spaces [2]. Interestingly, $\mathrm{CO}$ is produced endogenously at low concentrations with normal physiologic functions: smooth muscle cell relaxation, control of vascular tone [3], platelet aggregation [4], anti-inflammatory and anti-apoptotic events [5].

Endogenously, the oxidization of heme by the enzyme heme oxygenase $(\mathrm{HO})$ produces equimolar amounts of $\mathrm{CO}$, iron and biliverdin [6]. Heme is a major structural component of hemoglobin $(\mathrm{Hb})$, and the abundance of this molecule in red blood cells allows for the largest amount of heme for degradation. Additionally, $\mathrm{CO}$ has

\footnotetext{
* Correspondence: gns@queensu.ca

'Biomedical and Molecular Sciences, Queen's University, Kingston, ON, Canada

Full list of author information is available at the end of the article
}

been measured in a number of tissues; most abundantly in muscle, heart, liver, spleen, and kidney [7]; although both endogenous levels and functionality are not well understood.

Exogenous inhalation of $\mathrm{CO}$ leads to its preferential binding with $\mathrm{Hb}$, producing carboxyhemoglobin $(\mathrm{COHb})$. This binding is in direct competition with molecular oxygen $\left(\mathrm{O}_{2}\right)$, and binds to $\mathrm{Hb}$ with 250 times greater affinity than $\mathrm{O}_{2}[8]$. This effect shifts the $\mathrm{O}_{2}$ dissociation curve to the left [9], limiting the release of $\mathrm{O}_{2}$ to the tissues, and can lead to hypoxia, or further, the asphyxiating effects of $\mathrm{CO}$ poisoning. Measurable $\mathrm{CO}$ levels in non- smoking adults are 0 to $1.5 \% \mathrm{COHb}$ [10], whereas people who smoke may increase their $\% \mathrm{COHb}$ levels to $14 \%[11,12]$. Refer to Table 1 for a comparison of reference $\mathrm{CO}$ levels.

Although many negative effects are associated with cigarette smoking in pregnancy, $17 \%$ of Canadian women smoked cigarettes in their pregnancy between 1995 and 2001 [13]. Of the greater than 4800 toxic

\section{() Biomed Central}


Table 1 Reference Carbon Monoxide levels in humans and various environmental sources

\begin{tabular}{lll}
\hline Subject/Source & CO level & Source \\
\hline Non smoker & $0-1.5 \%$ COHb & {$[10]$} \\
\hline Smoker & Up to 14\%COHb & {$[11,12]$} \\
\hline \hline Natural urban air level & $1-30$ ppm & {$[15]$} \\
\hline Levels found in homes & $0.5-5$ ppm & {$[42]$} \\
\hline Cigarette Smoke & 20 000-60 000 ppm & {$[15]$} \\
\hline Alveolar Concentration in smoker & $300-400$ ppm & {$[15]$} \\
\hline $\begin{array}{l}\text { Car Exhaust without catalytic } \\
\text { converter }\end{array}$ & 30 000- 60000 & {$[15]$} \\
\hline
\end{tabular}

*Parts per million (ppm) by volume (100 ppm $=0.01 \%$ of $\mathrm{CO}$ in the air) *Percent carboxyhemoglobin (\% $\mathrm{COH} b)$ is the amount of $\mathrm{CO}$ bound to total haemoglobin

chemicals identified within cigarette smoke [14], a major combustible product is $\mathrm{CO}$. It readily crosses the placenta and can combine with fetal $\mathrm{Hb}$ and tissue heme moieties [15]. When pregnant sheep were exposed to $\mathrm{CO}$, a lag period was found before fetal $\mathrm{CO}$ levels began to rise, but shortly afterwards, they matched and even surpassed those of their mother. Fetal hypoxia may result at high levels of maternal $\mathrm{CO}$ exposure, however, the level at which maternal $\mathrm{CO}$ exposure becomes a fetal threat is unknown.

In vitro, researchers have isolated $\mathrm{HO}$ in human placental and umbilical cord tissues [16], suggesting that $\mathrm{CO}$ is produced in this tissue. We have shown that $\mathrm{CO}$, at levels similar to those found in umbilical cord blood at delivery, is capable of placental vasorelaxation [17]. As the levels of $\mathrm{CO}$ in pregnant women who smoke are increased, this suggests an exacerbation of placental vasorelaxation, while we have shown that nicotine has no effect on the basal feto/placental perfusion pressure [18]. These results suggest that CO may play a role in placental development and/or its regulation of placental hemodynamics [19].

A few studies have examined the effects of $\mathrm{CO}$ exposure in pregnancy, but they yield conflicting results in different animal species [20-23]. Studies conducted in pregnant wister rats exposed dams to one $\mathrm{CO}$ dose above $1000 \mathrm{ppm}$ for varying lengths of time throughout pregnancy, observing decreased fetal weights and litter size $[20,21]$. It is likely at such high exposures that $\mathrm{CO}$ poisoning occurred, however venous CO levels (57\% $\mathrm{COHb}$ recorded) were measured only in one of the studies, with no mention of the method by which this number was obtained [21]. Studies conducted at 500 ppm CO and below [22-24] yield maternal \% $\mathrm{COHb}$ levels of roughly 28 [7], approximating more closely \% $\mathrm{COHb}$ of adults smoking roughly two packs of cigarettes/day (up to 14\%) [25]. The results from each of these studies are difficult to compare, as dosing mechanisms, lengths and amounts of $\mathrm{CO}$ concentrations given to the animals vary between groups.

In the present study, we hypothesized that $\mathrm{CO}$ would be embryotoxic. We investigated the effect of chronic $\mathrm{CO}$ exposure to mice in pregnancy, and sought the level at which no maternal or feto/embryotoxic effects were demonstrable.

\section{Methods}

\section{Ethics Statement}

Experimental procedures were carried out according to the University Animal Care Committee of Queen's University and was approved by the Queen's University Ethics Committee (REB no. Smith 2007-052- Or).

\section{Animals and Husbandry}

Timed matings of CD1 mice (Charles River, USA), female (6-8 weeks old) and males (5-7 weeks old), were performed overnight. Females were weighed and placed into a regulated CO-dosing chamber on GD1 (morning detection of a vaginal plug). Food and water were provided ad libitum.

\section{Carbon Monoxide Concentrations}

Concentrations of $\mathrm{CO}$ administered were $0,25,60,100$, 150, 200 250, 300 and 400 ppm in ambient air. At each concentration a minimum of six pregnant female mice were utilized. Room air was collected using a compressor (Panther Compact 106, Silent Air Compressor, Texas, USA) and passed through a Norgren air dryer (Littleton, CO USA). The dry air was mixed with $10 \%$ $\mathrm{CO}$ gas (Praxair, Kingston, ON) using flow meters (Alicat Scientific, Tucson, AZ USA), and adjusted to the specific $\mathrm{CO}$ concentration required, using a Gas Mixing software Program (Qubit Systems Inc, Kingston, ON). The air was bubbled through distilled water, reintroducing humidity levels of 40-50\% (animal care regulations), and monitored using a Humidity Sensor (Vernier relative humidity sensor, Mississauga, ON, CAN) and its software (Vernier Logger Lite Software, Mississauga, ON, CAN). This sensor also ensured the cage temperature was maintained at $25^{\circ} \mathrm{C}$. The air mixture was vented into a tightly- sealed plastic aquarium, in which the mouse cage was placed, and exhausted out of the chamber into the room's air filter system. The chamber air was changed a minimum of 10 times per hour (flow rate $7000 \mathrm{ml} / \mathrm{min}$ ). The cage was changed twice weekly by research personnel, at which time the $\mathrm{CO}$ administration was stopped (20 minute maximum). Air samples were collected at least twice weekly from the aquarium air- port, and measured using a gas-solid chromatography machine (GC) (Peak Performer 1, Palo Alto, San Francisco, USA), as previously described[26], ensuring $\mathrm{CO}$ levels matched the desired concentrations. 


\section{Experimental Procedure}

Female mice were anesthetised on GD17 by intraperitoneal injection of $10 \mathrm{mg} / \mathrm{g}$ of 2-2-2-Tribromoethanol (T48402, Sigma Aldrich, Canada). Upon reaching a surgical plane of anaesthesia, maternal blood was drawn by retro-orbital blood collection using a glass pipette, transferred to a microcentrifuge tube containing 10 microliter $(\mu \mathrm{l})$ of $1430 \mathrm{U} / \mathrm{ml}$ sodium heparin (Sigma Aldrich, H0777), and placed immediately on ice. Mice were then perfused (gravity perfusion) through the left ventricle for 15 minutes with either phosphate buffered saline (PBS) (minimum of four mice/experiment) or $4 \%$ paraformaldehyde (PFA) (minimum two mice/experiment).

\section{Blood CO measurement}

Hemoglobin was measured within 5 minutes of blood collection using a Hemocue Hb 201 (Hemocue, Sweden). Amber vials $(2 \mathrm{ml})$ (Sigma- Aldrich Ltd) capped (Chromatographic Specialties C223710C) with $8 \mathrm{~mm}$ silica septa (Chromatographic Specialties, C13302) and containing $20 \mu \mathrm{l}$ of $2 \%$ sulfosalycylic acid (Sigma Aldrich, Cat no. 86193) were purged with $21 \% \mathrm{O}_{2} / 5 \%$ $\mathrm{CO}_{2}$ /balance $\mathrm{N}_{2}$ (Praxair, Kingston, $\mathrm{ON}$ ) sent through a catalytic converter (to reduce any $\mathrm{CO}$ present). Between $0.1 \mu \mathrm{l}$ and $1 \mu \mathrm{l}$ of blood (depending on the level of $\mathrm{CO}$ administration) was added using a gas tight Hamilton syringe and repeater system (Hamilton, USA). Triplicate vials per blood sample were prepared and set on ice for 60-120 minutes. Carbon monoxide levels were read using a GC and expressed as a percentage of total $\mathrm{Hb}$ using the following equation:

$$
\% \mathrm{COHb}=(\operatorname{volCO} /(\mathrm{Hb} * 1.368)] * 100 \%[10]
$$

where "vol CO" is milliliters of $\mathrm{CO}$ bound to $1 \mathrm{~L}$ of blood, $\mathrm{Hb}$ is total $\mathrm{Hb}$ concentration in the blood $(\mathrm{g} / \mathrm{L})$ and 1.368 is the CO-binding capacity of $\mathrm{Hb}$ in millilitres per gram.

\section{PBS perfused mice}

Following a 15 minute perfusion, the uterus was dissected out, and all fetuses and their respective placentas (excluding gestational losses) were removed and weighed. Litter size was noted for each mouse. All fetuses and placentas were examined for gross morphological abnormalities. Fetal mortality was classified as early gestational demise (EGD), or as a late gestational death (LGD) (Figure 1). We classified EGD as a resorbed fetus, where no separate distinction existed between placenta and fetus (Figure 1A), while LGD was determined by a discernible fetus and placenta (Figure 1B). A normal fetus at gestation day 17 is shown in Figure $1 \mathrm{C}$.
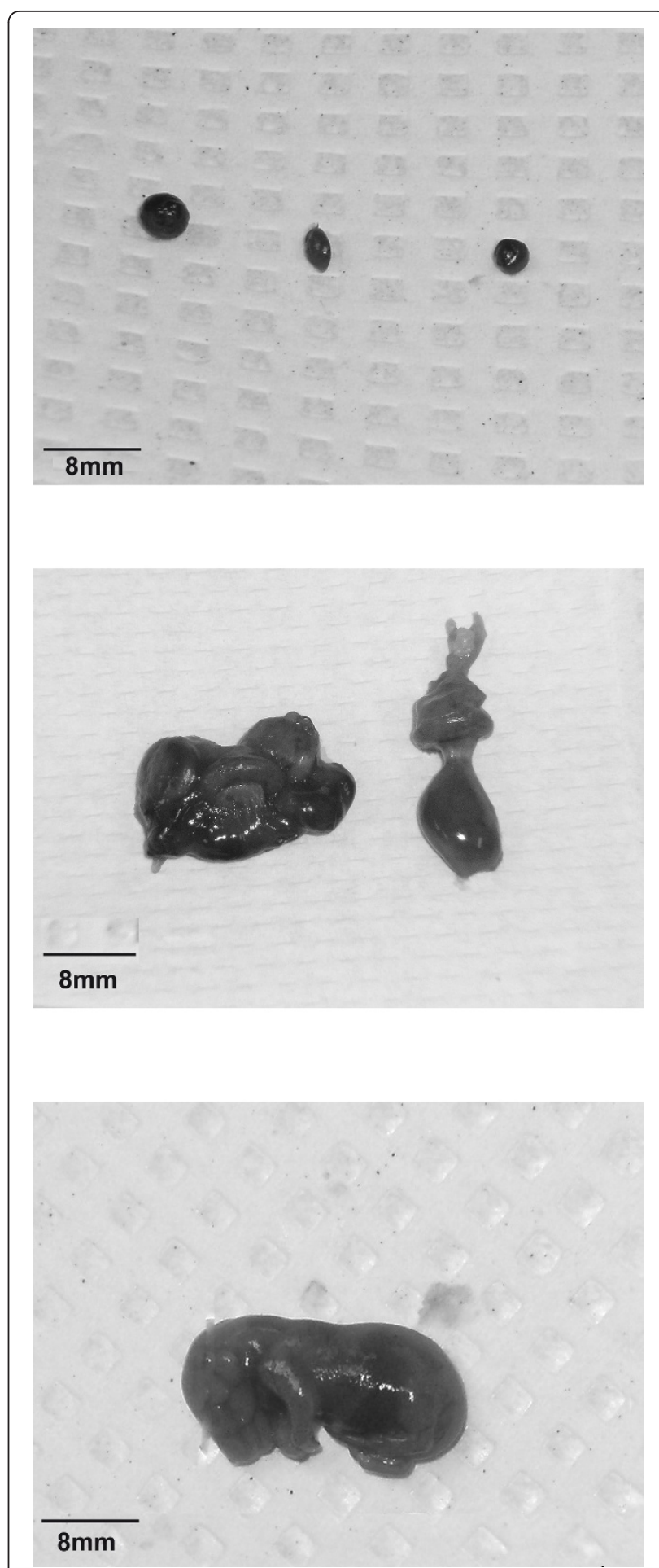

Figure 1 Representation of fetal early/late gestational death. A typical fetal early gestational demise is shown in A, a fetal late gestational death is shown in B, a normal fetus at GD17 is shown in C. 


\section{Fetal Blood Collection}

Three random fetuses were decapitated and blood was collected using a heparin-coated capillary tube (Fisher brand, Cat no. 22-260-950). The blood from the fetuses was pooled into a microcentrifuge tube and blood processing was completed as previously described for the dams.

\section{Tissue CO Levels}

Sections of maternal organs (brain, liver, lung, kidney, spleen, heart) and placenta were collected and placed on ice immediately. Tissue $\mathrm{CO}$ measurement was performed as per Vreman et al.[7].

\section{4\% PFA perfused mice}

A minimum of 2 mice per experiment were perfused with PFA. Following perfusion with 4\% PFA, the uterus was removed. Dissecting between implantation sites, three embryos were removed from each mouse's uterus, stored in 4\% PFA for 24 hours, and transferred to $70 \%$ ethanol until processing. Embryos were embedded in paraffin according to standard procedures.

Each embryo (six per CO concentration) was sectioned $(0.4 \mu \mathrm{m}$ thickness $)$ a minimum of 10 times in a saggital plane and placed on slides. Of the 10 slides, a random selection of 5 slides were chosen and stained with hematoxylin and eosin. Placentas were analyzed for histological morphometric changes compared to control. Three pictures were taken using Nikon Eclipse E800 Light Microscope and Q capture software of the whole placenta (10X and 40X magnification) as well as the placenta labyrinth (200X magnification). The placentas were analyzed for relative proportions of labyrinth versus junctional zone and alterations in cell shape and size. A third party anatomist was consulted on all histological slides analyses.

\section{Statistical Analysis}

Dose response curves for maternal/fetal \%COHb and $\mathrm{Hb}$ concentration were analyzed using linear regression analysis. The EGD and LGD data was analyzed with a chi squared test using the fisher exact method. EGD were compared to total implantation sites subtract EGD and LGD, while LGD were compared to live implantation sites subtract LGD. For this test, OpenEpi.com version 2.3.1 was used to analyze data. All other analyses were completed using a one way analysis of variance with a post-hoc Dunnett's multiple comparison test, using Graphpad prism version 6. A p-value less than 0.05 was deemed significant for all tests. All statistical results are reported with standard deviation.

\section{Results}

All of the required $\mathrm{CO}$ levels for this study were achieved using the computerized software and were confirmed using GC to be between 0.5 and $5.0 \mathrm{ppm}$ (up to $1.6 \%$ ) of the desired $\mathrm{CO}$ levels.

For each $\mathrm{CO}$ exposure, a minimum of four mice were perfused with PBS and two mice with PFA. The amount of litters per experimental group for the exposures of 0 , 25 and $60 \mathrm{ppm} \mathrm{CO}$ are larger than the remaining exposures. This was due to a slight change in protocol following the beginning of the study, where we developed a method to measure fetal blood $\mathrm{CO}$ levels. Therefore, we repeated the first three experiments at 0,25 and 60 ppm $\mathrm{CO}$, in order to acquire this data.

The blood \% $\mathrm{COHb}$ levels were positively correlated with increasing $\mathrm{CO}$ concentration exposure, for both maternal $(\mathrm{p}<0.01)$ and fetal $(\mathrm{p}<0.01)$ measurements (Figure $2 \mathrm{~A}$ ). The ratio of fetal/maternal \%COHb was a mean (SD) of 1.74X (0.12), beyond $25 \mathrm{ppm}$. Additionally, $\mathrm{Hb}$ followed the same trend as \% $\mathrm{COHb}$ levels, and was positively correlated with increasing $\mathrm{CO}$ concentrations for both maternal $(\mathrm{p}<0.01)$ and fetal $(\mathrm{p}<0.01)$ levels (Figure 2B).

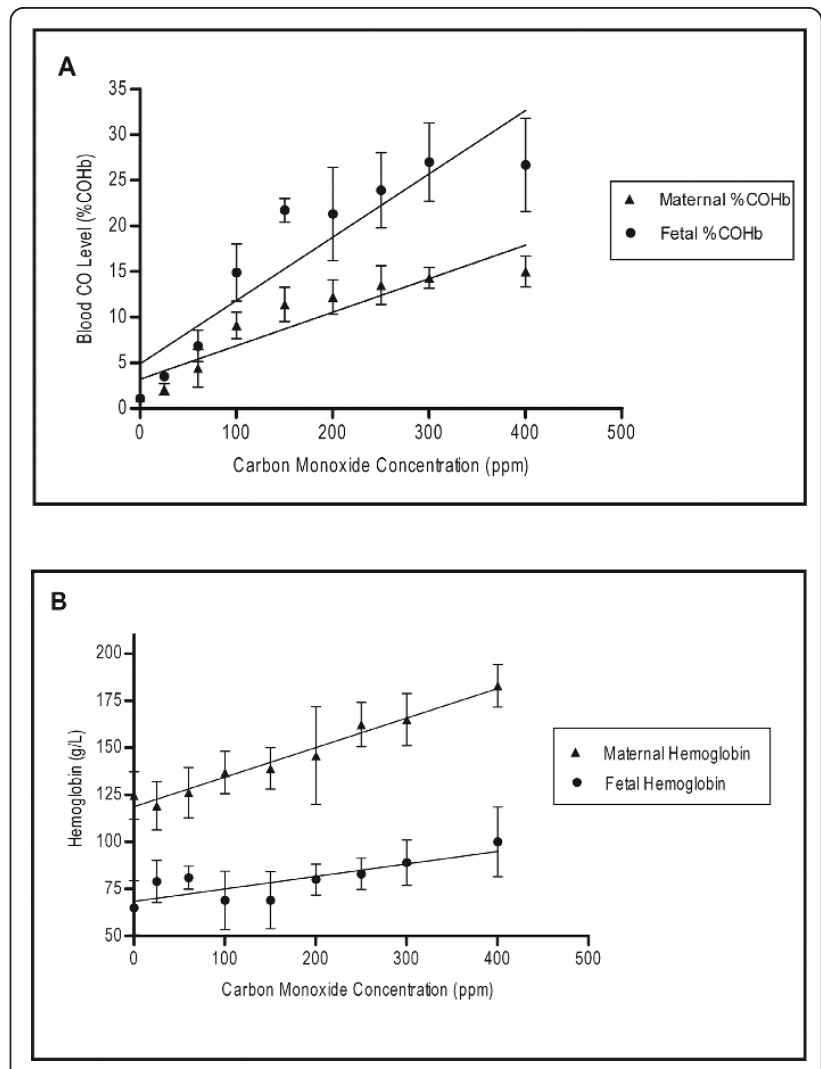

Figure 2 Dose responses of maternal/fetal $\mathrm{Hb}$ and $\mathrm{CO}$ levels to increasing maternal exogenous $\mathrm{CO}$ exposure. A positive trend was observed with both maternal and fetal blood \% $\mathrm{COHb}$ vs. $\mathrm{CO}$ concentration exposure (A). A positive trend was observed with both maternal and fetal $\mathrm{Hb}$ vs. $\mathrm{CO}$ concentration exposure (B).The slope of the line significantly deviated from zero in both cases, $A$ and $B(p<0.05)$. 
Mean fetal mass did not differ compared to control with $\mathrm{CO}$ concentrations of $25 \mathrm{ppm}$ to $300 \mathrm{ppm}$ (Figure 3A). At $400 \mathrm{ppm} \mathrm{CO}$, fetal mass was significantly lower than that of the control $(\mathrm{p}<0.05)$. Placental mass was not found to be significantly different than the control with any of the $\mathrm{CO}$ doses $(\mathrm{p}>0.05)$ (Figure 3B). Litter size was significantly reduced only at $400 \mathrm{ppm}$ compared to control $(\mathrm{p}<0.05)$ (Table 2).

In Table 2, total implantation sites/litter did not differ between experimental $\mathrm{CO}$ exposures. The number of EGD and LGD increased with maternal CO exposure. EGD is presented as EGD/(total implantation sitesEGD) $* 100 \%$ and LGD is presented as LGD/[total implantation sites- (LGD + EGD)]*100\%. A significant increase in number of fetal EGD was observed at 300 and $400 \mathrm{ppm}$, while LGD were found to be significant compared to control at $400 \mathrm{ppm}(\mathrm{p}<0.05)$. Relative risk data and confidence intervals are listed in Table 2.

Figure 4 displays the tissue $\mathrm{CO}$ concentration in the maternal heart, liver, lung, kidney and brain, for each
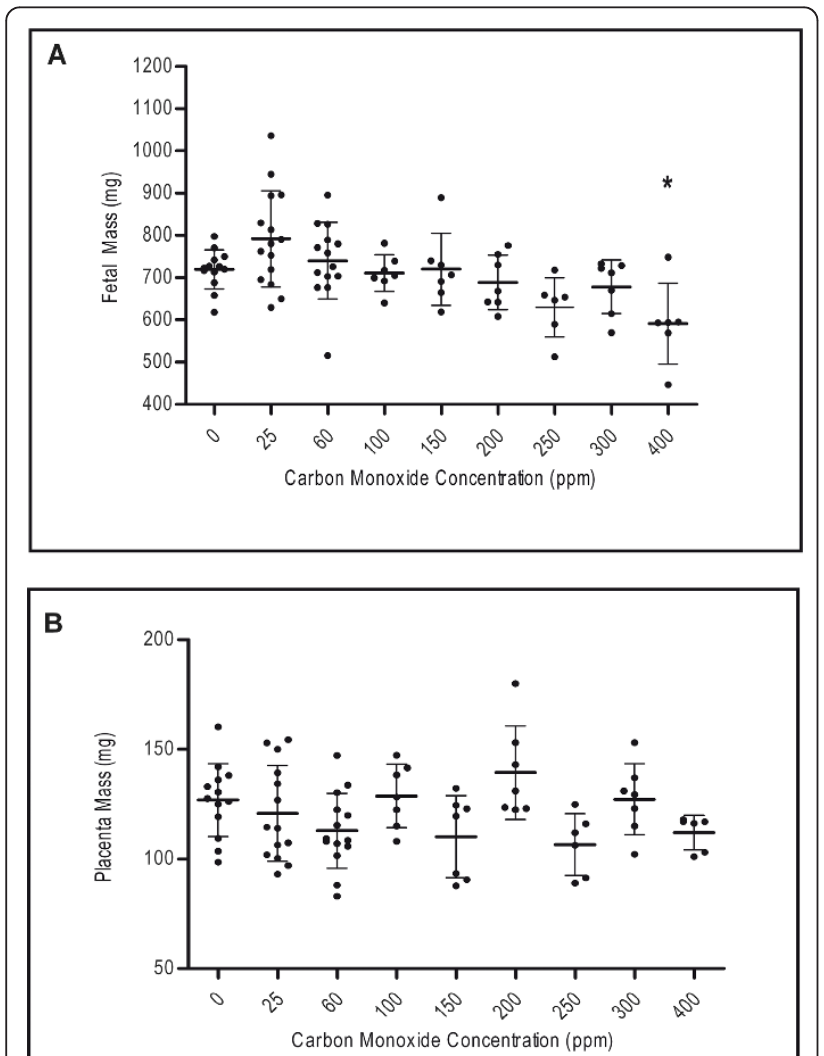

Figure 3 Comparison of mean fetal and placental mass to maternal exogenous $\mathrm{CO}$ exposure. Mean fetal mass for each CO exposure level is displayed in figure $\mathrm{A}$, with a significant decrease in mass observed only at 400 ppm (* $p<0.05$ ). Mean placental mass for each $\mathrm{CO}$ exposure level is displayed in figure $\mathrm{B}$; no significance at any of the CO exposures was observed ( $p>0.05)$.
$\mathrm{CO}$ exposure. An elevation in tissue $\mathrm{CO}$ concentration is observed for most tissues, as maternal $\mathrm{CO}$ exposure increases. Figure 5 displays the $\mathrm{CO}$ levels in the placenta and maternal spleen for each $\mathrm{CO}$ exposure. These organs are shown separately as they contained at least four times the $\mathrm{CO}$ level as the other tissues examined. At $60 \mathrm{ppm}$ CO exposure, significant differences $(\mathrm{p}<$ 0.05 ) are observed in both tissue samples, compared to control tissue.

Blinded histological analysis of placental tissue did not show any gross morphological differences between those exposed to CO and controls (data not shown). All parties analyzing histological slides noted no differences in relative amounts of labyrinth versus junctional zone. Additionally, no alterations in cell shape and size were observed.

\section{Discussion}

A number of studies have evaluated the effects of $\mathrm{CO}$ exposure on pregnancy; however a direct comparison of these studies is difficult because of significant methodologic differences. For example, the method of $\mathrm{CO}$ delivery varied from whole body[20-22] to nose-only inhalation [27], time exposure (acute vs. chronic) differed; daily time intervals or specific days of gestation. The dosing concentrations differed, with some studies evaluating $\mathrm{CO}$ levels of $1000 \mathrm{ppm}$ to $10000 \mathrm{ppm}$ [20,28], well above the toxic range. No previous study has correlated maternal/ fetal CO levels with maternal/fetal outcomes. Our study's aim was to use a highly regulated $\mathrm{CO}$ chamber system to expose pregnant mice to chronic $\mathrm{CO}$ concentrations throughout gestation, that would mimic those of smoking adults $(2-14 \% \mathrm{COHb})[25]$.

Maternal cigarette smoking is perhaps one of the most common chronic methods by which $\mathrm{CO}$ levels are increased, thereby exposing the fetus to greater than normal CO levels. Our laboratory has measured a range of $\mathrm{COHb}$ in maternal smokers of $1.5-9.85 \% \mathrm{COHb}$ (unpublished), while a level of $14 \% \mathrm{COHb}$ has been determined previously by other researchers $[11,12]$. Cigarette smoke contains an average of $4 \%$ or 40000 ppm CO by volume [29], and during the smoking process it becomes diluted in air, leaving the alveoli to see roughly 400-500 ppm [15]. It is known that $\mathrm{CO}$ can cross the placenta, therefore $\mathrm{CO}$ can affect the fetal partial pressure of $\mathrm{O}_{2}\left(\mathrm{pO}_{2}\right)$ [15].

In the present study, the highest dose of $\mathrm{CO}$ yielded a mean maternal \%COHb level of 15.6 , while women who smoke heavily during pregnancy have a calculated $\mathrm{CO}$ level of up to $14 \% \mathrm{COHb}[11,12]$. It is important to note that in comparison with women who intermittently smoke, and thus are affected by peaks and troughs of high $\mathrm{CO}$ exposure, these mice were subjected to elevated $\mathrm{CO}$ concentrations on a constant basis. The 
Table 2 The effect of maternal CO exposure on total number of early gestational demise/late gestational death

\begin{tabular}{ccccccc}
\hline CO (ppm) & Total Implantation sites/litter & Total live fetuses/litter & ${ }^{* *}$ EGD (\%) & RR of EGD (Cl) & ${ }^{* *}$ LGD (\%) & RR of LGD (Cl) \\
\hline $\mathbf{0}$ & 12.8 & 12.6 & 1.12 & & 0.56 & \\
\hline $\mathbf{2 5}$ & 12.2 & 11.9 & 2.40 & $2.15(0.42,10.95)$ & 0.48 & $0.86(0.05,13.66)$ \\
\hline $\mathbf{6 0}$ & 12.8 & 12.4 & 1.81 & $1.62(0.27,0.96)$ & 1.20 & $2.16(0.20,23.56)$ \\
\hline $\mathbf{1 0 0}$ & 14.2 & 13.9 & 0.78 & $0.70(0.06,7.63)$ & 1.56 & $1.40(0.09,22.15)$ \\
\hline $\mathbf{1 5 0}$ & 13.6 & 13.5 & 0.92 & $0.82(0.08,8.95)$ & 0.00 & 0.00 \\
\hline $\mathbf{2 0 0}$ & 10.9 & 10.5 & 1.15 & $1.03(0.09,11.19)$ & 2.30 & $1.74(0.38,44.76)$ \\
\hline $\mathbf{2 5 0}$ & 12.9 & 12.4 & 2.91 & $2.67(0.44,15.34)$ & 0.90 & $1.74(0.11,27.49)$ \\
\hline $\mathbf{3 3 0}$ & 13.9 & 12.1 & $8.80^{*}$ & $7.88(1.78,34.92)$ & 4.00 & $7.16(0.85,60.54)$ \\
\hline $\mathbf{4 0 0}$ & 13.7 & $8.2^{*}$ & $13.40^{*}$ & $12.01(2.72,52.94)$ & $26.83^{*}$ & $48.02(6.59,350.20)$ \\
\hline
\end{tabular}

EGD: early gestational demise LGD: late gestational death RR: relative risk

$\mathrm{Cl}$ : confidence interval

Statistical Analysis: Chi squared test, using the fisher exact method to compare EGD or LGD to total implantation sites - EGD or LGD and analysis of variance for live fetuses/litter ( $\left.{ }^{*} \mathrm{p}<0.05\right)$.

**Equations: EGD (\%): Total EGD/(Total Implantation Sites- EGD)*100, LGD (\%): Total LGD/[(Total Implantation Sites-(EGD + LGD)]*100

half- life of $\mathrm{CO}$ is $2-3$ hours when breathing room air [15], therefore a smoker would have peak CO levels directly following their smoking a cigarette, which would slowly dissipate until the next cigarette. Also of importance are the elevated ventilation and elimination rates, along with increased $\mathrm{CO}$ uptake, present in smaller mammals compared to humans [30]. As explained by Klimisch et al.[30], the higher ventilation rates by smaller mammals allow for a faster rate of $\mathrm{Hb}$ saturation by $\mathrm{CO}$. Therefore, the \% $\mathrm{COHb}$ results observed in this study are presumably higher than those that would be seen in women under similar exposure. The \% $\mathrm{COHb}$ values cannot be evaluated directly, but can be used as representative values to compare the mouse model with the potential effects in pregnant women.

As an adaptation response to increased CO levels, likely in part due to hypoxia, it is documented that mammals will increase $\mathrm{Hb}$ concentration [31] in order

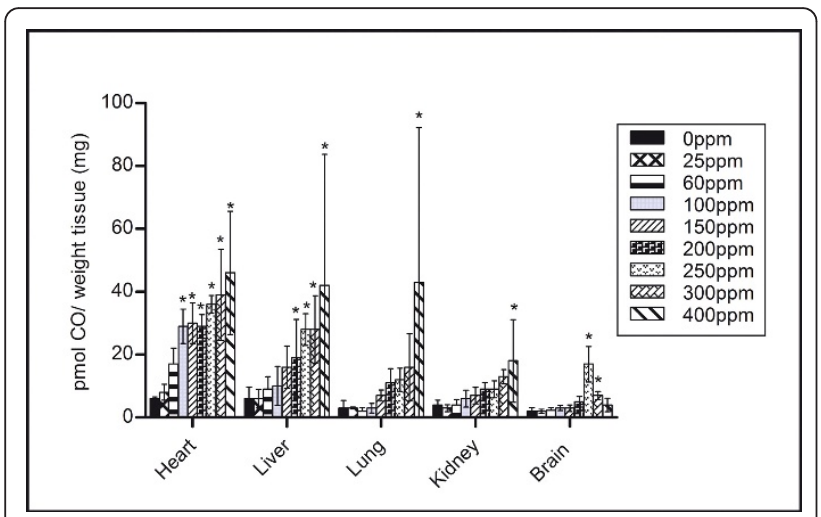

Figure 4 Maternal tissue CO levels in heart, liver, lungs, kidney and brain for each $\mathrm{CO}$ exposure. Significance was found in the heart tissue at CO levels $\geq 100$ ppm, in the liver at CO levels $\geq 200$ ppm, in both the lung and kidney at the CO level of 400 ppm only and finally in the brain at CO levels of 250 and 300 ppm only ( $p<0.05$ ). to increase the $\mathrm{O}_{2}$ carrying capacity of the blood. A significant dose- response was observed with both the maternal and fetal $\mathrm{Hb}$ to increasing $\mathrm{CO}$ exposure levels, and one would expect a similar response in pregnant women.

The ratio between maternal and fetal \% $\mathrm{COHb}$ concentrations (1.74) is in agreement with a study conducted by Longo and Hill [32], and similar to results recorded by Bureau et al.[33] who showed that the ratio of fetal/ maternal $\mathrm{COHb}$ was 2.5 (using umbilical blood as a fetal representative value). The $\mathrm{Hb}$ levels of both maternal and fetal systems differ and the affinity of fetal $\mathrm{Hb}$ for $\mathrm{CO}$ is established to be higher than that of the maternal system [12]. This, coupled with the lower $\mathrm{pO}_{2}$ in capillary blood of the fetus versus maternal system [12], would add to the effect of increased fetal \% $\mathrm{COHb}$ compared to maternal \% $\mathrm{COHb}$.

There is considerable variability in the effects of $\mathrm{CO}$ exposure on fetal birth weight in the published literature. It is well established that pregnant women who

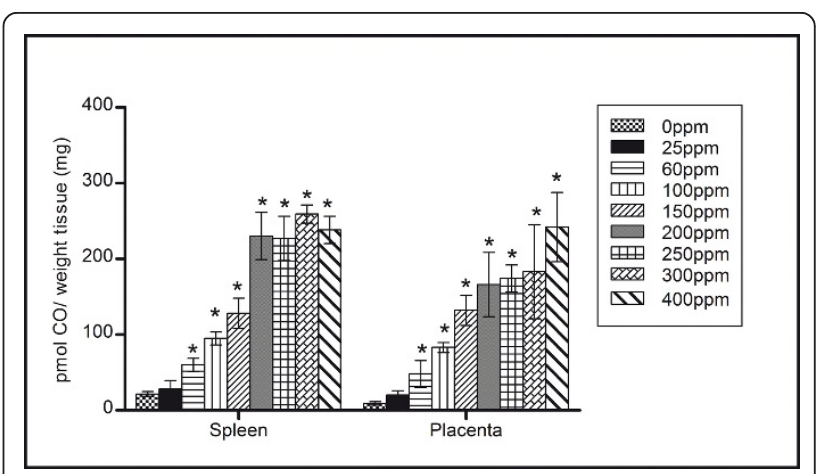

Figure 5 Placenta and maternal spleen tissue CO levels with increasing CO exposure. Compared to control, significance was observed in both placenta and spleen at $\mathrm{CO}$ levels $\geq 60$ ppm exposure $\left({ }^{*} p<0.05\right)$. 
smoke cigarettes will give birth to a neonate roughly 200 $\mathrm{g}$ lighter (per pack per day smoked) than a fetus born to a non- smoking mother [34]. However, given that there are thousands of toxic substances in cigarette smoke, the specific role of $\mathrm{CO}$ in these situations cannot be determined. Wouters et al [28] and Soothill et al.[35] studied the human effects of increased fetal $\mathrm{COHb}$ on fetal weight, with conclusions in both cases that data was not convincing for a simple cause-effect relationship. Our study found a significant decrease in birth weight compared to control only at our highest $\mathrm{CO}$ dose. Other studies have also found a decrease in birth weight with increasing $\mathrm{CO}$ exposure [20-23]. Singh and Scott found that subjecting pregnant CD-1 mice (on GD 8 to GD 18) to CO exposures of 0 to $500 \mathrm{ppm}$ (controlling chamber levels using a $\mathrm{CO}$ monitor), lead to a significant decrease in fetal weight as early as $125 \mathrm{ppm}$, but not in a dose dependent manner [24]. This study did not measure $\mathrm{CO}$ levels in either maternal or fetal mice. Given the toxic effects demonstrated by Singh and Scott as early as $125 \mathrm{ppm}$, which conflicts with our data, this presents a possibility of fetal adaptation to $\mathrm{CO}$ exposures when subjected from conception, rather than mid- way through pregnancy. Future studies would be necessary to further examine this hypothesis.

Interestingly, placental weight was not significantly different than the control at any of the $\mathrm{CO}$ doses. Bissonnette and Wickham [36] reported that placental CO diffusing capacity increased significantly with greater gestational age, and correlated with fetal weight but not placental weight. Thus, as $\mathrm{CO}$ levels increased across our experiment, no correlation was expected with placental weight. Litter size (number of healthy fetuses) however, was significantly decreased at $400 \mathrm{ppm} \mathrm{CO}$ exposure compared to control. In previous studies, litter size in rats was not shown to be affected when dams were chronically exposed to $150 \mathrm{ppm} \mathrm{CO}$ throughout gestation [37], but was decreased when dams were exposed to acute doses of 1000 to $1600 \mathrm{ppm}$ twice daily throughout pregnancy [20]. An increase in EGD and LGD above 180 ppm maternal CO exposure has been reported previously in varying animal models [23,24], although $\mathrm{CO}$ exposure levels and dosing schedules were different amongst them. In our study, while EGD proved significant compared to control at $300 \mathrm{ppm}$, at $400 \mathrm{ppm}$, more fetuses appeared to have died in late gestation. As the placenta's diffusing capacity increases with gestational age [38], perhaps fetal health was more greatly compromised later in pregnancy with higher $\mathrm{CO}$ doses, as more potent $\mathrm{CO}$ was able to diffuse to the fetal circulation.

Maternal tissue $\mathrm{CO}$ levels proved that aside from $\mathrm{Hb}$, the gas was also accumulating in the heme- containing molecules found throughout tissue. At 0 ppm $\mathrm{CO}$, tissue
CO levels closely approximated those previously reported [7]. Both the spleen and the placenta were the most difficult tissues to perfuse, as their open circulation proved difficult for the complete removal of blood. This would explain the much higher $\mathrm{CO}$ levels compared to the other tissues sampled. A dose response was observed in both tissues. Of the remaining tissues measured, the heart expressed the highest $\mathrm{CO}$ concentration, possibly due to high myoglobin content, a heme containing protein with an affinity for $\mathrm{CO}$ second only to $\mathrm{Hb}$ [39].

In this study, at $400 \mathrm{ppm}$ maternal $\mathrm{CO}$ exposure, a number of toxic results were noted. Compared to control, both maternal and fetal \% $\mathrm{COHb}$ and $\mathrm{Hb}$ values were significantly increased, fetal birth weight and litter size were significantly decreased, and EGD/LGD were significantly increased. Maternal tissue $\mathrm{CO}$ levels increased as $\mathrm{CO}$ doses were raised, lending to the highest measurable $\mathrm{CO}$ amounts at $400 \mathrm{ppm}$. These results indicate that the chronic $\mathrm{CO}$ exposure to pregnant mice, at levels above $300 \mathrm{ppm}$, results in a feto-toxic effect.

Recently, $\mathrm{CO}$ has come into light as a possible therapeutic, due to its many beneficial effects: endogenous and exogenous $\mathrm{CO}$ can promote angiogenesis[40], suppress the release of anti-angiogenic markers[41], decrease inflammation and apoptotic events[5], and vasodilate blood vessels[16]. These beneficial properties of $\mathrm{CO}$ may be helpful in the treatment of disorders concerning angiogenesis and vascularity, including those in pregnancy. This study is of great importance as we have identified a fetal toxic threshold of $\mathrm{CO}$ in pregnancy above $300 \mathrm{ppm}$ maternal exposure. This information can be used in future experimental designs, when examining the potential beneficial properties of $\mathrm{CO}$ exposure to treat disorders of pregnancy.

\section{Conclusions}

Our study indicates that exposure to levels at or below 300 ppm CO throughout pregnancy has little demonstrable effect on fetal growth and development in the mouse.

\footnotetext{
Abbreviations

$\mathrm{CO}$ : carbon monoxide; \%COHb: percent carboxyhemoglobin; $\mathrm{HO}$ : heme oxygenase; $\mathrm{Hb}$ : haemoglobin; O2: oxygen; GC: gas chromatography; $\mu$ : microliter; EGD: early gestational demise; LGD: late gestational death; PBS: phosphate buffered saline; PFA: paraformaldehyde.

\section{Acknowledgements}

This study was supported by the Physicians' Services Incorporated Foundation http://www.psifoundation.org/ (Grant number 09-37 - "Effect of Carbon Monoxide on Placental Function and Development") (to G.N.S.); a Queen's Graduate Award and a McLaughlin Fellowship Award (to C.C.V) The funders had no role in study design, data collection and analysis, decision to publish, or preparation of the manuscript.

Findings presented in part at the $56^{\text {th }} \mathrm{SGl}$ Annual meeting, Glasgow, Scotland March 2009 and the $57^{\text {th }}$ SGI Annual Scientific Meeting, Orlando, USA, March 26, 2010
} 


\section{Author details}

'Biomedical and Molecular Sciences, Queen's University, Kingston, ON, Canada. ${ }^{2}$ Obstetrics and Gynecology, Kingston General Hospital, Kingston, ON, Canada.

\section{Authors' contributions}

CCV, RC and GNS participated in the design of the study. CV and RC carried out all mouse procedures. CCV carried out all analysis and preparation of histology, blood and tissue samples. The manuscript was drafted by CCV and reviewed and edited by GNS. Statistical analysis was performed by CCV, and reviewed by GNS. All authors read and approved the manuscript.

\section{Competing interests}

The authors declare that they have no competing interests.

Received: 3 October 2011 Accepted: 14 December 2011 Published: 14 December 2011

\section{References}

1. Von BR: Carbon monoxide. J Appl Toxicol 1999, 19:379-386

2. Weaver LK: Carbon monoxide poisoning. Crit Care Clin 1999, 15:297-317, viii.

3. Wang R: Resurgence of carbon monoxide: an endogenous gaseous vasorelaxing factor. Can J Physiol Pharmacol 1998, 76:1-15.

4. Brune $B, U$ Ulrich V: Inhibition of platelet aggregation by carbon monoxide is mediated by activation of guanylate cyclase. Mol Pharmacol 1987 , 32:497-504.

5. Song R, Kubo M, Morse D, Zhou Z, Zhang X, Dauber JH, et al: Carbon monoxide induces cytoprotection in rat orthotopic lung transplantation via anti-inflammatory and anti-apoptotic effects. Am J Pathol 2003, 163:231-242.

6. Bainbridge SA, Smith GN: HO in pregnancy. Free Radic Biol Med 2005, 38:979-988.

7. Vreman HJ, Wong RJ, Kadotani T, Stevenson DK: Determination of carbon monoxide (CO) in rodent tissue: effect of heme administration and environmental CO exposure. Anal Biochem 2005, 341:280-289.

8. Benesch RE, Maeda N, Benesch R: 2,3-Diphosphoglycerate and the relative affinity of adult and fetal hemoglobin for oxygen and carbon monoxide. Biochim Biophys Acta 1972, 257:178-182.

9. Douglas CG, Haldane JS, Haldane JB: The laws of combination of haemoglobin with carbon monoxide and oxygen. J Physiol 1912, 44:275-304.

10. Vreman HJ, Stevenson DK, Zwart A: Analysis for carboxyhemoglobin by gas chromatography and multicomponent spectrophotometry compared. Clin Chem 1987, 33:694-697.

11. Heron $\mathrm{HJ}$ : The effects of smoking during pregnancy: a review with a preview. N Z Med J 1962, 61:545-548.

12. Longo LD: Carbon monoxide in the pregnant mother and fetus and its exchange across the placenta. Ann N Y Acad Sci 1970, 174:312-341.

13. Miller WJ, Hill G: Pregnancy and Smoking. 53-56. 4-7-2004. Health Reports. 30-1-2011., Ref Type: Report.

14. Green $C R$, Rodgman A: A half century of advances in analytical methodology of tobacco and its products. 1996, 131-304.

15. Longo LD: The biological effects of carbon monoxide on the pregnant woman, fetus, and newborn infant. Am J Obstet Gynecol 1977, 129:69-103.

16. Lyall F, Barber A, Myatt L, Bulmer JN, Robson SC: Hemeoxygenase expression in human placenta and placental bed implies a role in regulation of trophoblast invasion and placental function. FASEB J 2000, 14:208-219.

17. Bainbridge $S A$, Farley $A E$, McLaughlin BE, Graham CH, Marks GS, Nakatsu K, et al: Carbon monoxide decreases perfusion pressure in isolated human placenta. Placenta 2002, 23:563-569.

18. Bainbridge SA, Smith GN: The effect of nicotine on in vitro placental perfusion pressure. Can J Physiol Pharmacol 2006, 84:953-957.

19. Bainbridge SA, Sidle EH, Smith GN: Direct placental effects of cigarette smoke protect women from pre-eclampsia: the specific roles of carbon monoxide and antioxidant systems in the placenta. Med Hypotheses 2005, 64:17-27.

20. Tachi N, Aoyama M: Effect of cigarette smoke and carbon monoxide inhalation by gravid rats on the conceptus weight. Bull Environ Contam Toxicol 1983, 31:85-92.
21. Tachi N, Aoyama M: Effect of restricted food supply to pregnant rats inhaling carbon monoxide on fetal weight, compared with cigarette smoke exposure. Bull Environ Contam Toxicol 1986, 37:877-882

22. Astrup P, Olsen HM, Trolle D, Kjeldsen K: Effect of moderate carbonmonoxide exposure on fetal development. Lancet 1972, 2:1220-1222.

23. Schwetz BA, Smith FA, Leong BK, Staples RE: Teratogenic potential of inhaled carbon monoxide in mice and rabbits. Teratology 1979, 19:385-392.

24. Singh J, Scott LH: Threshold for carbon monoxide induced fetotoxicity. Teratology 1984, 30:253-257.

25. Wald NJ, Idle M, Boreham J, Bailey A: Carbon monoxide in breath in relation to smoking and carboxyhaemoglobin levels. Thorax 1981 36:366-369.

26. Vreman HJ, Kwong LK, Stevenson DK: Carbon monoxide in blood: an improved microliter blood-sample collection system, with rapid analysis by gas chromatography. Clin Chem 1984, 30:1382-1386.

27. Carmines EL, Rajendran N: Evidence for carbon monoxide as the major factor contributing to lower fetal weights in rats exposed to cigarette smoke. Toxicol Sci 2008, 102:383-391.

28. Wouters EJ, de Jong PA, Cornelissen PJ, Kurver PH, van Oel WC, van Woensel CL: Smoking and low birth weight: absence of influence by carbon monoxide? Eur J Obstet Gynecol Reprod Biol 1987, 25:35-41.

29. Osborne JS, Adamek S, Hobbs M: Some components of gas phase of cigarette smoke. Analytical Chemistry 1956, 28:211-215.

30. Klimisch HJ, Chevalier HJ, Harke HP, Dontenwill W: Uptake of carbon monoxide in blood of miniture pigs and other mammals. Toxicology 1975, 3:301-310.

31. Chen KC, Lee EW, McGrath JJ: Effect of intermittent carbon monoxide inhalation on erythropoiesis and organ weights in rats. J App/ Toxicol 1984, 4:145-149.

32. Longo LD, Hill EP: Carbon monoxide uptake and elimination in fetal and maternal sheep. Am J Physiol 1977, 232:H324-H330.

33. Bureau MA, Monette J, Shapcott D, Pare C, Mathieu JL, Lippe J, et al: Carboxyhemoglobin concentration in fetal cord blood and in blood of mothers who smoked during labor. Pediatrics 1982, 69:371-373.

34. Wang X, Tager IB, Van VH, Speizer FE, Hanrahan JP: Maternal smoking during pregnancy, urine cotinine concentrations, and birth outcomes. A prospective cohort study. Int J Epidemiol 1997, 26:978-988.

35. Soothill PW, Morafa W, Ayida GA, Rodeck CH: Maternal smoking and fetal carboxyhaemoglobin and blood gas levels. Br J Obstet Gynaecol 1996, 103:78-82.

36. Bissonnette $\mathrm{JM}$, Wickham WK: Placental diffusing capacity for carbon monoxide in unanesthetized guinea pigs. Respir Physiol 1977, 31:161-168.

37. Fechter $L D$, Annau Z: Toxicity of mild prenatal carbon monoxide exposure. Science 1977, 197:680-682.

38. Longo LD, Ching KS: Placental diffusing capacity for carbon monoxide and oxygen in unanesthetized sheep. J Appl Physiol 1977, 43:885-893.

39. Piantadosi CA: Biological chemistry of carbon monoxide. Antioxid Redox Signal 2002, 4:259-270.

40. Li VG, Sacerdoti D, Sangras B, Vanella A, Mezentsev A, Scapagnini G, et al: Carbon monoxide signaling in promoting angiogenesis in human microvessel endothelial cells. Antioxid Redox Signal 2005, 7:704-710.

41. Cudmore M, Ahmad S, Al-Ani B, Fujisawa T, Coxall H, Chudasama K, et al: Negative regulation of soluble Flt-1 and soluble endoglin release by heme oxygenase-1. Circulation 2007, 115:1789-1797.

42. United States Environmental Protection Agency: An Introduction to Indoor Air Quality (IAQ): Carbon Monoxide (CO). 22-5-2011. 5-5-2011., Ref Type: Online Source.

\section{Pre-publication history}

The pre-publication history for this paper can be accessed here: http://www.biomedcentral.com/1471-2393/11/101/prepub

\section{doi:10.1186/1471-2393-11-101}

Cite this article as: Venditti et al:: Effects of chronic carbon monoxide exposure on fetal growth and development in mice. BMC Pregnancy and Childbirth 2011 11:101. 